\title{
7
}

\section{Videoconference Teaching for Graduate Courses in Educational Administration}

\author{
Ken Brien \\ University of New Brunswick
}

One of the "tidal dilemmas" addressed by the 2009 Society for Teaching and Learning in Higher Education conference concerned physical vs. virtual learning environments. Videoconference teaching is an alternative to traditional classroom instruction and a subset of the broader field of distance education. Based on my recent experiences with videoconference teaching, this paper explores the application of videoconference teaching to graduate students in educational administration, with reference to the nature of both the subject matter and the learners.

$\mathrm{I}^{\mathrm{n}}$ $\mathrm{n}$ today's age of widely available information and communication technologies, it is not surprising that videoconference technology is being used to deliver some university courses and programs. This technology is particularly attractive for the delivery of graduate programs to students for whom an on-campus, face-to-face course is less accessible for a variety of reasons. Moreover, for those pursuing graduate studies in educational administration, the nature and context of the learners and the needs of the school system provide encouragement for the delivery of courses and programs by various distance education formats, including videoconference teaching.

Between the Fall 2006 and Winter 2009 terms, I had the opportunity to teach the following three graduate courses in educational administration to a total of six classes via videoconference: Admin- istrative Theory I, Educational Theory and School Administration, and Legal Aspects of Education. In each of the six classes, the course was delivered to students at two sites - the Fredericton campus and the Saint John campus of the University of New Brunswick (UNB). The majority of these students were enrolled in the Master's of Education (M.Ed.) program in Educational Administration at UNB, most of them practicing teachers in the $\mathrm{K}-12$ system who were studying part-time by taking evening courses. Total class enrollment averaged 14 students, with a range of 10 to 19 students per term, and there were approximately equal numbers of students at each site. In this paper, I share my reflections on the teaching and learning experience in light of selected literature on videoconference teaching and with reference to the nature of the subject matter and the learners.

Videoconference instruction can be consid- 
ered a subset of the broader field of distance education and an alternative to the traditional classroom setting. As such, it presents both challenges and opportunities for learners and educators alike. These include issues associated with educational quality, learning communities, and technological resources. Educational quality is a common concern in distance education. Alsunbul (2002) reported on issues with student perceptions of distance education, largely based on previous experiences during the era of university correspondence courses. In their examination of educational quality correlates in online graduate programs, Millson and Wilemon (2008) identified four major concepts to assess educational quality: dialogue, structure, access, and flexibility. Similarly, Kanuka and Kelland (2008) questioned some of the claims made by proponents of e-learning, particularly associated with the creation of learning communities and the quality of the learning experience. Given that videoconference instruction is a lesser-used technology compared to online learning, Bloomberg (2007) noted that there is limited research in the area of collaborative learning experiences of adults and how to facilitate them through participation in videoconference programs. Bezeau and Lipsett (1994) described the use of interactive television as an early application of videoconference instruction for the delivery of a graduate course in administrative theory at UNB in 1993.

\section{Educational Quality}

Educational quality considerations were important in my decision to offer graduate courses by videoconference. Given my experience with teaching in the traditional classroom, my perception of a quality teaching and learning experience was guided by my practices and beliefs as applied in that setting. As a result, in my planning for videoconference teaching, I attempted to replicate as closely as possible the important elements of the strategies, interactions, and activities that I would normally use in the traditional classroom. Since these were graduate courses, in which the emphasis was on engaging students in thinking with each other about ideas in an active and critical fashion, I wanted to ensure that the videoconference format would allow that. This meant, for example, that it was important for me to ensure that the cameras at both sites were set up to maximize interaction among students during discussions, rather than placing the focus solely on me as the lecturer. I wanted to create an instructional setting that resembled, as much as possible within the videoconference format, my perception of a "real" classroom.

Some of my students expressed to me a similar desire. Some had taken other graduate courses by audio conference or in an online format, but they preferred live interaction with an instructor and with classmates. At the same time, a traditional classroom setting at one site, most often in Fredericton, was not as accessible to those living closer to the Saint John campus, located about an hour's drive away. Those students desiring a quality learning experience, as provided by the videoconference format, now had the opportunity to receive it at either of two locations.

Alsunbul (2002) commented, in reference to the quality of distance education programs, on the importance and influence of instructor training and dispositions as well as the perceptions of students. I needed to be willing to learn to use the videoconference technology and to do so in the interests of those students who could not come to the Fredericton campus to take these courses, but who lived closer to the Saint John campus. Similarly, my students at both sites had to be comfortable with the use of the technology and a learning setting in which either the instructor or half of their classmates or both were not present in the immediate classroom, but located at a remote site.

\section{Learning Community}

A major challenge often cited in distance education literature is student engagement. Videoconference instruction provided a means of building a learning community and a sense of connection and engagement among members of my classes in both sites. Bloomberg (2007), who researched the factors and conditions perceived to foster and inhibit the formation and development of a learning community 
through videoconferencing, found that instructor beliefs were an important factor in faculty members' perceptions of learning communities. Consistent with my pedagogical beliefs, I employed a number of strategies to encourage the creation of a learning community.

One of these strategies was to encourage interaction among students with their classmates at the other site. This is consistent with Millson and Wilemon's (2008) view of dialogue as a key element in educational quality. To promote dialogue and interaction among the students, I would often present a topic for the students to discuss in small groups at each site; following that discussion, I would have the students from each group share highlights of their discussion with the whole class. While the cameras would be focused on me when presenting the discussion topic, I would adjust the cameras for the whole class debriefing so that the students at each site were looking at, and speaking to, each other. During student-led group presentations, I emphasized that the students ensure their classmates at the other site were able to participate fully in the discussion and other activities. I modelled some strategies for accomplishing that - for example, specifically posing questions and watching and listening carefully for questions and comments from the students at the remote site. Also key was ensuring that the students at the opposite site had received all the materials being used during my presentations or student presentations.

Another important strategy for me was instructor presence at both sites. Since I was located in Fredericton, I conducted most classes from that site. However, at least three times each term, I travelled to the Saint John campus to lead the class from there. This allowed me to meet my Saint John students in person, and convey to them that they were important to me as well. These trips gave them the chance, for example, to discuss their assignments with me and have some additional interaction with me after the formal videoconference lesson was concluded. Many of the Saint John students took advantage of my visits to talk to me about their M.Ed. program and ask for advice on course selections and program planning.

My third strategy was to plan a closing activity for the course in which the students would meet face to face at one site for the final class of the term. In all these courses, the major assignment was a term paper in which students would apply their understanding of course concepts to an issue or situation from their professional experience. During the final class, students would give an oral presentation and present a poster or some other visual display on the topic of their major term paper as a means of sharing their learning with their peers. I would provide some light refreshments as part of this culminating activity. In my experience, students seemed to enjoy meeting their classmates from the other site after seeing them throughout the term on a video screen. These and other strategies were intended to ensure that all students felt connected to their peers and to me in a manner similar to a traditional classroom.

\section{Technological Resources}

Videoconference instruction, like any form of distance education, requires reliable technology that is accessible to students, usable by instructors, and designed to support learning (Alsunbul, 2002). Bezeau and Lipsett (1994) listed equipment such as two telephone lines, a document camera, a videocassette player, and a fax machine to teach by interactive television in 1994. In a prophetic comment regarding video quality, they observed as follows: "The solution to poor video resolution, high definition television, is on the horizon but will probably not be in widespread use until after the end of the century" (p. 3). By contrast, I had access to an Internet connection to transmit data between the two sites, so that I could display PowerPoint slides on my computer and onto a large screen in both sites. I could also post PowerPoint slides and other materials on the Blackboard site for the course, thus allowing students to preview visual materials prepared by me or by their peers before class.

In both sites, the various controls for the videoconference technology were reasonably userfriendly for students and for me. When I conducted the class from the Fredericton site, there was an undergraduate student assistant employed at the Saint John site to turn on the equipment and provide assis- 
tance to me and to my students. When I conducted the class from Saint John, I would ask willing students to operate the equipment in Fredericton. This was usually limited to ensuring that the relevant cameras were directed properly, and the intended images on the screen were appearing correctly. Since most of my students were practising elementary and high school teachers, they were normally able to perform routine equipment operations and some troubleshooting procedures.

However, access to technical support was a source of concern for us on several occasions. A recurring problem for each of the courses was unexpected lost connections between the two sites. This happened quite regularly - almost predictably at times - and was usually easily corrected. However, on occasion, it was necessary for the student assistant in Saint John to completely reboot the equipment at that site before we could re-establish the videoconference connection. Since these classes were conducted during the evening, the full-time classroom support staff members were not available and the student assistant had only limited training and scope for intervention. As a result, there were class meetings that ended prematurely, with students being asked to conclude some discussions on their own at the remote site. The presence of a classroom telephone at each site allowed me to contact the students at the other site when such problems arose to make alternate arrangements.

A significant access issue associated with currently available videoconference technology is that we were limited to only two sites. Since the Fredericton and Saint John campuses are located approximately $100 \mathrm{~km}$ apart, this extended the reach of these three courses to students living and working within reasonable proximity to either site. However, this did not help those students living in other areas of the province. This requires faculty members planning to deliver videoconference courses to choose two sites each term on the basis of such factors as student demand, instructor preference, and available technology. Since teachers from all school districts in New Brunswick require graduate courses to pursue advanced certification, particularly those seeking leadership positions, UNB's Faculty of Education has a mandate and responsibility to find ways to serve students located far from campus. While the availability of videoconference instruction has been welcomed by those able to benefit from it, the present limit of two sites is a constraint to more frequent use, which has led to more use of audio-conference and online formats for distance delivery of our graduate courses.

\section{Student Comments and Instructor Reflection}

Through the student opinion survey conducted for each course at UNB, I received some feedback on student experiences with this format. While most appreciated the use of technology and my visits to both sites, a few students found the technology and my presence at the other site distracting, with the observation that students in the same location as the instructor tended to dominate the class discussion. This latter point reinforces for me the need not only to visit both sites, but to attend specifically to the engagement of students in both sites at all times. My experience with videoconference instruction supports the proposition that this technology can foster the teaching and learning needs of graduate students in educational administration. Issues of quality, community, and technology can be addressed by appropriate choices, efforts, and perceptions of instructors, students, and technical staff so that videoconference instruction can be an effective delivery format.

\section{References}

Alsunbul, A. (2002). Issues related to distance education in the Arab world. Convergence, 35(1), 59-80.

Bezeau, L.M. \& Lipsett, F. (1994). Teaching an administrative theory course with interactive television. New Brunswick Educational Administrator, 29, 1-8.

Bloomberg, L.D. (2007). Culture and community: Case study of a video-conferenced graduate 
distance education program. Journal of Distance Education, 22(1), 41-58.

Kanuka, H. \& Kelland, J. (2008). Has e-learning delivered on its promises? Expert opinion on the impact of e-learning in higher education. Canadian Journal of Higher Education, 38(1), 45-65.

Millson, M.R. \& Wilemon, D. (2008). Educational quality correlates in online graduate management education. Journal of Distance Education, 22(3), 1-18.

\section{Biography}

Ken Brien is an Associate Professor in the Faculty of Education at the University of New Brunswick. His teaching and research interests include educational administration, school law, professional learning communities, and parent-teacher interactions in schools. 